\title{
Cerebellar Function and Dysfunction-What Did We Learn from 4th International Symposium, Society for Research on the Cerebellum in Japan?
}

\author{
Noriyuki Koibuchi
}

Published online: 28 December 2011

(C) Springer Science+Business Media, LLC 2011

\section{Introduction}

On 18 September 2011, 4th International Symposium, Society for Research on the Cerebellum (SRC) was held in Sanjo Conference Hall at the University of Tokyo, Tokyo, Japan. Approximately 100 researchers attended the symposium. Although the symposium was ended with a great success, there may be several issues that need to be considered for the continuation of the symposium.

The idea of having the symposium in Japan in 2011 was first discussed in 2008, during the inaugural SRC symposium in Geneva. In 2009, the local organizing committee was organized with following members:

Chair Shoji Tsuji (University of Tokyo)

Vice Chair Kazuyoshi Tsutsui (Waseda University)

Yoshikazu Ugawa (Fukushima Medical University)

Secretary Noriyuki Koibuchi (Gunma University)

By the third SRC symposium in Amsterdam, the outline of fourth symposium was determined and invitation speech was made by Dr. Koibuchi during the third symposium. The theme of the symposium was set as "Cerebellar Function and Dysfunction".

Until March 2011, all preparation for fourth symposium went well. With the efforts of local organizing committee members, donations from several companies including

\footnotetext{
N. Koibuchi $(\bowtie)$

Department of Integrative Physiology,

Gunma University Graduate School of Medicine,

3-39-22 Showa-machi,

Maebashi, Gunma 371-8511, Japan

e-mail: nkoibuch@med.gunma-u.ac.jp
}

Springer were made, which contributed greatly to manage the symposium. Then, an unexpected disaster occurred in March 11. The Great East Japan Earthquake with magnitude 9.0 hit east coast of Japan. The earthquake and tsunami killed more than 15,000 people. In addition, a nuclear power plant in Fukushima was seriously damaged by tsunami, causing a leakage of radioisotopes. After the disaster, many national and international conferences that were planned to be held in Japan were cancelled. The local organizing committee members of fourth SRC symposium also discussed whether the symposium should be cancelled. However, the members concluded that it is very important to have an international symposium in Tokyo to prove that Japan is coming back. Then, letters of invitation were resent to all speakers and most of them agreed to give a talk. The registration of the symposium has started on March 7. In addition to plenary talk, five symposia, and luncheon seminar, 28 posters were registered.

\section{Symposium Program}

On September 18, the symposium was started with welcoming remarks from Drs. Ferdinando Rossi, president of the SRC, and Shoji Tsuji, chair of local organizing committee. Then, scientific sessions were followed:

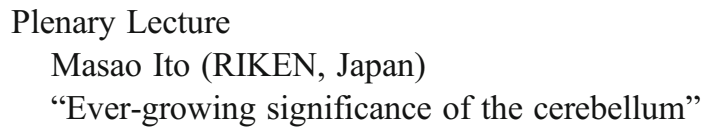

Symposium 1: Cerebellar Development and Regeneration

1. Ferdinando Rossi (University of Turin, Italy) "Specification and differentiation of cerebellar GABAergic neurons" 
2. Mikio Hoshino (National Institute of Neuroscience, Japan)

"Roles of transcription factors in specifying neuron subtypes in the cerebellar system"

3. David Vaudry (INSERM, France)

"Role of the peptide PAPCAP in the cerebellar development"

4. Kazuyoshi Tsutsui (Waseda University, Japan)

"Neurosteroid biosynthesis and action during cerebellar development"

Symposium 2: Synaptic Plasticity of Cerebellum

1. Masanobu Kano (University of Tokyo, Japan)

"Activity-dependent maturation of climbing fiber to Purkinje cell synapses during postnatal cerebellar development"

2. Tomoo Hirano (Kyoto University, Japan)

"Regulation of inhibitory synaptic plasticity in a Purkinje neuron"

3. Timothy Ebner (University of Minnesota, USA)

"Functional interactions between parallel fibers and parasagittal zones"

4. Michisuke Yuzaki (Keio University, Japan)

"The ins and outs of GluD2-Why and how Purkinje cells use the special glutamate receptor"

\section{Luncheon Seminar}

Hideyuki Okano (Keio University, Japan)

"Brain Science using iPS technologies and transgenic non-human primates"

Symposium 3: Molecular Basis of Cerebellar Structure and Function

1. Jan Voogd (Erasmus Medical Center, Netherlands)

"The modular organization of the cerebellum. History and future"

2. Jean Mariani (UPM, France)

"The nuclear receptor RORalpha: a critical actor in the neuron-astrocyte dialogue"

3. Mario Manto (FNRS-ULB, Belgium)

"Cerebellar Research: Two centuries of discoveries"

Symposium 4: Cerebellar Functional Analysis

1. Mary Uusisaari and Thomas Knopfel (RIKEN, Japan)

"Cellular diversity in the deep cerebellar nuclei"

2. Izumi Sugihara (Tokyo Medical and Dental University, Japan)

"Cerebellar functional and anatomical connection"
3. Shinji Kakei (Tokyo Metropolitan Institute of Medical Science, Japan)

"Contribution of the cerebellum to the feedforward and feedback controllers for tracking movement of the wrist"

4. Yoshikazu Ugawa (Fukushima Medical University, Japan)

"Cerebellar stimulation in humans"

Symposium 5: Recent Advances of Research on Human Cerebellum and Disease Models

1. Im Joo Rhyu (Korea University, South Korea)

"Macroscopic and microscopic changes of cerebellum in response to motor skill learning in human and animal models"

2. Hirokazu Hirai (Gunma University, Japan)

"Rescue of developmental defects in mice with cerebellar ataxia using lentiviral vectors"

3. Ichiro Miyai (Morinomiya Hospital, Japan)

"Challenge of neurorehabilitaion for cerebellar degenerative diseases"

4. Shoji Tsuji (University of Tokyo, Japan)

"Molecular genetic approaches toward understanding the multiple system atrophy"

During the poster session, five distinguished posters were selected and awarded as "Masao Ito Prize". The presenting author and titles are as follows:

Masao Ito Prize posters (numbers do not indicate ranking)

1. Haraguchi et al.

"Estradiol promotes Purkinje dendritic growth, spinogenesis and synaptogenesis during neonatal life by inducing the expression of BDNF"

2. Hirata et al.

"Direct causality between single Purkinje cell activities and motor learning revealed by a cerebellummachine interface utilizing VOR adaptation paradigm"

3 and 4. Yamada et al./Seto et al.

"Spatial specification of cerebellar neuroepithelium by bHLH transcription factors, Ptfla and Atoh1, during development/transcription factors expressed in the Purkinje cell lineage" (joint award of two posters from the same laboratory)

5. Mikuni et al.

"Activity-dependent synapse elimination of climbing fiber of Purkinje cell projections in vitro" 


\section{Future Perspectives}

Although fourth SRC symposium was held only 6 months after the Great East Japan Earthquake, almost 100 cerebellar researchers attended. The quality of all presentation was excellent and thus the discussion was very active. The success of the fourth SRC symposium, which was first held in Asian region, has contributed greatly for promoting SRC in this region. It is also effective in appealing to the world that Japan is coming back to normal and safe to visit. One of the issues regarding the organization of international symposia by societies such as SRC aiming to promote sciences is to maintain the budget stable and to manage expenses. The SRC budget is currently positive. In addition, in Japan, several companies supported the symposium. For example, Springer supported a part of expense for reception and provided congress bag and pen; Mitsubishi Tanabe Pharma Co. supported for luncheon seminar. However, such support may not be always available in all regions. The support to future annual meeting must be considered carefully, in order to maintain this objective of the society. Another issue is timing. Previous two symposia in Europe were held in conjunction with the Federation of European Neuroscience Symposium, whereas another symposium in the USA was held with Society for Neuroscience. In Japan, it was held as a satellite symposium of Japan Neuroscience Meeting. In future, SRC symposium may be also held as a satellite for such large meetings. However, it may be also possible to have the symposium separately with longer period. In such case, the symposium may be held biennially.

Overall, SRC gathers an outstanding panel of scientists. It is a unique opportunity to build novel knowledge and create collaborations. Annual symposium plays a major role in such SRC activities.

Acknowledgments SRC committee and the local organizing committee members thank all cerebellar researchers who attended the symposium. Particularly, we appreciate greatly for those who attended from abroad. We are also grateful for all companies and organizations supported the symposium.

Conflicts of interest There are no conflicts of interest in this submission. 